\title{
PENGUJIAN DAYA HANTAR LISTRIK AIR TANAH DI SEKITAR TEMPAT PEMBUANGAN AKHIR GUNUNG TUGEL KABUPATEN BANYUMAS MENGGUNAKAN PRINSIP JEMBATAN WHEATSTONE
}

\author{
Sehah dan Wahyu Tri Cahyanto \\ Program Studi Fisika, Fakultas Sains dan Teknik, Universitas Jenderal Soedirman \\ Jalan dr. Suparno No. 61 Karangwangkal Purwokerto \\ E-mail: sehahallasimy@yahoo.co.id
}

\begin{abstract}
Electrical conductivity of groundwater have been measured in area about the final garbage dismissal place (TPA) of Gunung Tugel, Regency of Banyumas. Groundwater samples have been taken away from 104 point of groundwater sources which distributed around of the research area, consisted of well water, belik water and pump water. Then, water samples are tested in Electronics and Instrumentation laboratory, Faculty of Science and Technique, UNSOED use the Wheatstone bridge principle. Electrical conductivity of groundwater obtained, then mapped pursuant to position of samples points location, so that obtained map of electrical conductivity contour of groundwater in research area. Pursuant to the electrical conductivity contour map, known that the mean electrical conductivity value in research area is $0,0594 \mathrm{k}^{-1}$, where highest electrical conductivity value is $0,1449 \mathrm{k} \Omega^{-1}$ and lowest electrical conductivity value is $0,0209 \mathrm{k}^{-1}$. Pursuant to interpretation known that most liquid waste (leacheat) of TPA Gunung Tugel are indicated flow into south and south-west area (Village of Kedungrandu) owning lower topography.
\end{abstract}

Keywords: Final garbage dismissal place (TPA) of Gunung Tugel, liquid waste (leacheat), electrical conductivity (DHL).

\section{PENDAHULUAN}

Salah satu permasalahan sampah di Purwokerto, yang hingga kini dampak ekologisnya masih terasa adalah pengelolaan sampah di Tempat Pembuangan Akhir (TPA) Gunung Tugel. Meskipun sekarang sudah dibatasi, namun selama kurang lebih dua puluh lima tahun (sejak tahun 1984), TPA Gunung Tugel hanya sekedar difungsikan untuk menampung sampah, tanpa dilengkapi sarana dan fasilitas untuk memisahkan sampah organik dan anorganik serta tidak ada sarana pengolahan dan pembuangan limbah cair sampah atau air lindi (Koran Sore Wawasan, 2006). Air lindi (leachate) adalah cairan hasil pembusukan sampah yang banyak mengandung organisme, senyawa kimia, ion-ion dan sebagainya. Limbah cair ini meresap ke dalam celah dan pori-pori tanah bersama air hujan, sehingga masuk ke dalam aliran air tanah, sesuai siklus air di alam. Akibatnya kualitas air tanah menurun hingga ke tingkat minimum, sehingga air tidak berfungsi sesuai dengan peruntukkannya (Noriko, 2003 dan Lubis, 2006).

Secara administratif, lokasi TPA Gunung Tugel terletak di zona perbatasan Kelurahan Karangklesem, Kecamatan Purwokerto Selatan dan Desa Kedungrandu, Kecamatan Patikraja, Kabupaten Banyumas. Sedangkan secara geologis, lokasi ini terletak di atas cekungan dengan struktur batuan yang disebut dengan formasi Tapak. Formasi Tapak terdiri dari lapisan batuan pasir berbutir kasar berwarna kehijauan dan conglomerate yang bercampur batuan breksi andesit local di bagian bawah. Sedangkan bagian atas berupa batuan pasir gampingan dan napal berwarna 
hijau yang bercampur dengan kepingan molusca. Formasi Tapak di lokasi ini diperkirakan memiliki kedalaman hingga 500 meter. Oleh karena itu, air tanah yang telah tercemar oleh limbah cair (air lindi) dapat masuk ke dalam sumur penduduk terutama yang berada di dalam zona formasi Tapak (Asikin dkk., 1992).

Salah satu upaya untuk menindaklanjuti permasalahan ini adalah dengan melakukan pengujian Daya Hantar Listrik (DHL) air tanah di daerah sekitar TPA Gunung Tugel. DHL air tanah terkait dengan kandungan logam dan ion-ion, yang diperkirakan berasal dari limbah cair (air lindi) hasil pembusukan sampah di TPA selama kurun waktu yang lama. Oleh karena itu jika DHL air tanah yang diperoleh tinggi, maka diduga telah terjadi intrusi limbah cair (air lindi) ke dalam sumber air atau manifestasi air tanah di daerah sekitar TPA Gunung Tugel. Masalah ini perlu diwaspadai dan diantisipasi karena berdampak buruk terhadap kesehatan manusia. Dengan dukungan data geologi setempat, dapat dilakukan analisis dan interpretasi untuk mengungkap pola penyebaran limbah cair bawah permukaan di daerah sekitar TPA Gunung Tugel.

Limbah cair sampah (air lindi) diindikasikan banyak mengandung senyawa asam, basa dan garam. Senyawa-senyawa tersebut jika dilarutkan ke dalam air, dapat terpecah menjadi ion positif dan ion negatif, yang dinamakan elektrolit. Jika di dalam larutan elektrolit dimasukkan dua elektroda yang dihubungkan dengan kutub positif dan kutub negatif sumber arus searah atau bolak-balik, maka dapat timbul medan listrik di antara kedua elektroda tersebut. Akibatnya ion positif bergerak ke elektroda negatif untuk mengambil elektron dari elektroda ini, dan ion negatif bergerak ke elektroda positif untuk menyerahkan elektron ke elektroda ini. Hal ini berarti bahwa di dalam larutan elektrolit terjadi konduksi muatan dari satu elektroda ke elektroda lainnya melalui pengangkutan ion-ion.

Jika $n_{+}$adalah jumlah ion positif, $n$ - adalah jumlah ion negatif, $q$ adalah muatan ion, $v_{+}$dan $v_{\text {- }}$ adalah laju ion positif dan negatif (drift velocity) ke satu arah serta $A$ adalah luas penampang bagian yang harus dilalui arus, maka besar arus listrik yang mengalir adalah (Staf Lab. Fisika Dasar UGM, 2005) adalah

$i=\left(n_{+} q v_{+}+n_{-} q v_{-}\right) A$

Besar laju ion $v_{+}$dan $v_{-}$tergantung dari medan listrik dan jenis ion, yang dapat dirumuskan sebagai

$v_{+}=\mu_{+} E$ dan $v_{-}=\mu_{-} E$

dengan $\mu_{+}$dan $\mu_{\text {- adalah tetapan yang }}$ disebut mobilitas ion positif dan ion negatif, sedangkan $E$ adalah kuat medan listrik. Substitusi persamaan (2) ke persamaan (1) diperoleh hubungan

$i=A\left(n_{+} \mu_{+}+n_{-} \mu_{-}\right) z e E$

dimana $q=z e$, dengan $z$ adalah nomor atom dan $e$ adalah muatan elektron.

Jika tegangan antara dua elektroda adalah $V$ dan panjang larutan elektrolit adalah $l$, maka kuat medan listriknya dapat dinyatakan sebagai

$E=\frac{V}{l}$

Dengan demikian, jika $n_{+}=n_{-}=n$, maka persamaan (1) dapat ditulis menjadi

$i=\frac{A}{l} z e n\left(\mu_{+}+\mu_{-}\right) V$

Untuk larutan tertentu dengan panjang dan luas penampang efektifnya tertentu, maka nilai $z$ e $n\left(\mu_{+}+\mu_{\text {- }}\right)$ adalah tetap. Jika $Y$ adalah Daya Hantar Listrik (DHL) dan $R$ adalah hambatan listrik, maka dapat ditulis suatu persamaan

$\frac{A}{l} z e n\left(\mu_{+}+\mu_{-}\right)=\frac{l}{R}=Y$

Sedangkan konduktivitas listriknya dapat dirumuskan 
$\sigma=\frac{l}{A} Y=\frac{l}{A R}=z e n\left(\mu_{+}+\mu_{-}\right)$

Sehingga daya hantar listriknya adalah

$Y=\frac{1}{R}=\frac{z e n A\left(\mu_{+}+\mu_{-}\right)}{l}$

Daya Hantar Listrik $(Y)$ memiliki satuan $\Omega^{-1}$ (Staf Lab. Fisika Dasar UGM, 2005) dan ini merupakan parameter fisika yang ingin diujikan terhadap sampel air tanah di sekitar TPA Gunung Tugel, Purwokerto.

\section{METODE PENELITIAN}

Penelitian yang dilakukan ini termasuk kategori survei. Sampel air tanah diambil dari daerah sekitar TPA
Gunung Tugel, sedangkan pengujian DHL air tanah dilakukan di Laboratorium Elektronika dan Instrumentasi, Fakultas Sains dan Teknik, UNSOED, Purwokerto. Waktu pelaksanaan penelitian adalah selama empat bulan, yaitu mulai pada bulan Juni hingga September 2007. Bahan yang diperlukan dalam penelitian adalah sampel air yang diambil langsung dari seluruh manifestasi air tanah di sekitar lokasi TPA Gunung Tugel, berupa sumur, belik (sumber air menyerupai lubang sumur yang digali di dasar sungai, hutan atau sawah) dan pompa air. Adapun skema peralatan penelitian yang digunakan dapat dilihat pada Gambar 1.

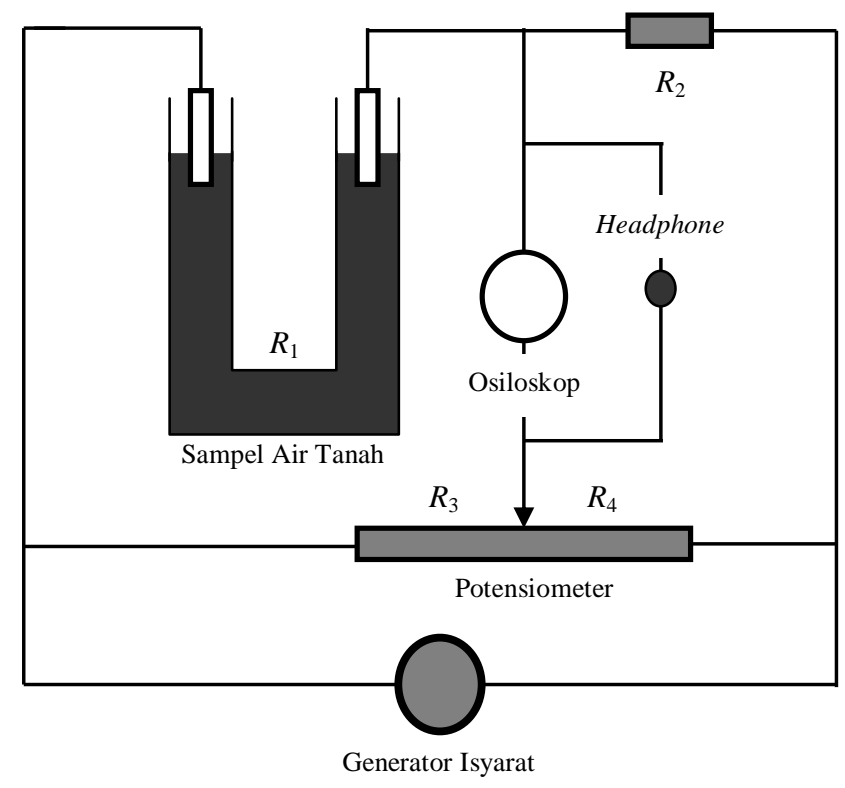

\section{Keterangan:}

$\mathrm{R}_{1}=$ tahanan elektrolit

$\mathrm{R}_{2}=$ tahanan buzzer

$\mathrm{R}_{3}=$ tahanan potensiometer bagian kiri

$\mathrm{R}_{4}=$ tahanan potensiometer bagian kanan

Gambar 1. Skema peralatan pengujian DHL sampel air menggunakan prinsip jembatan Wheatstone.

Urutan kegiatan yang dilakukan dalam penelitian ini dapat dilihat pada diagram alir (flowchart) Gambar 2. Sedangkan pengujian DHL sampel air tanah digunakan prinsip jembatan Wheatstone. Untuk pengujian, sumber arus listrik yang digunakan adalah sumber tegangan bolak-balik dari osilator atau generator isyarat. Adapun prosedur pengujian DHL air tanah dapat dilihat pada diagram alir seperti Gambar 3. 


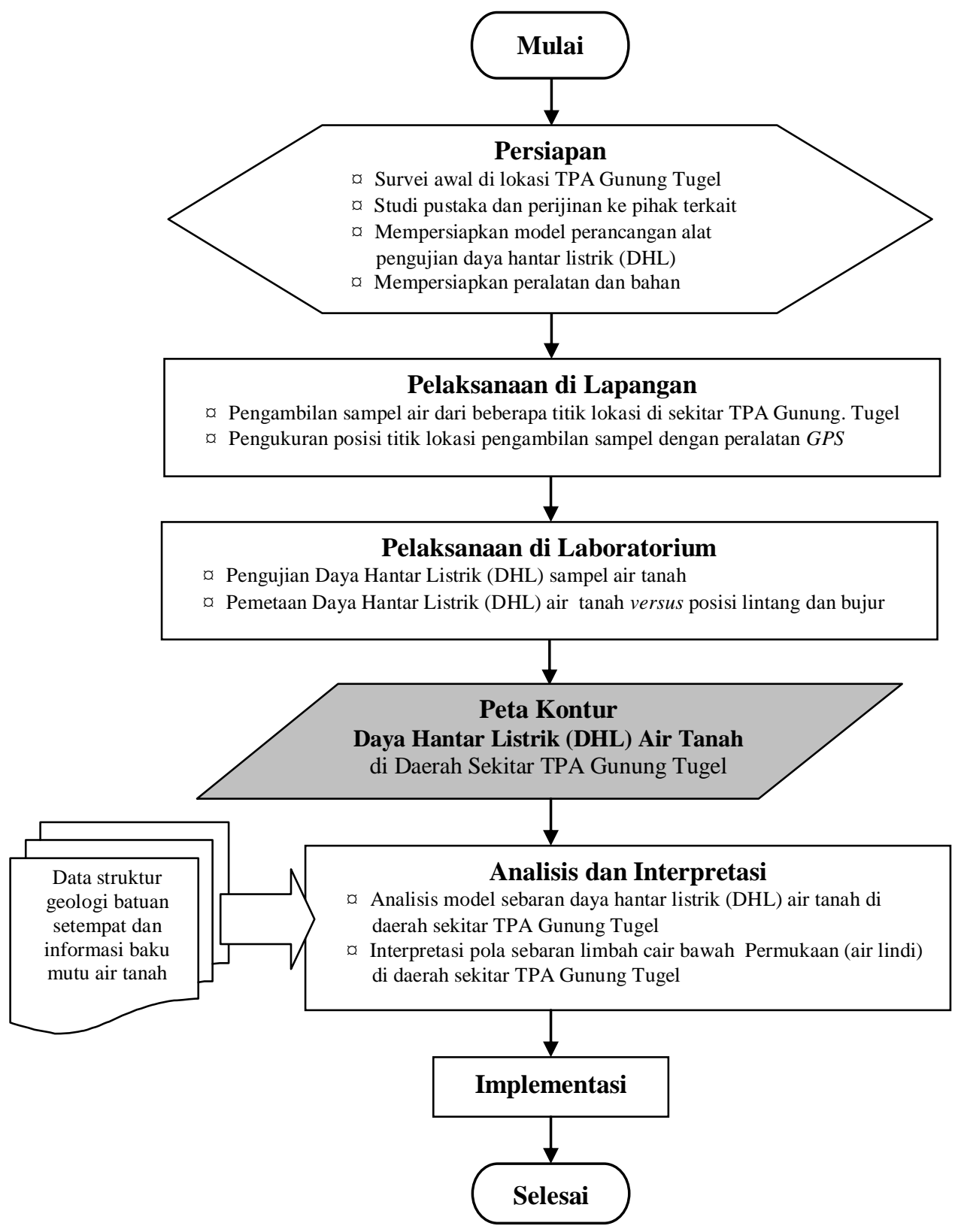

Gambar 2. Diagram alir urutan kegiatan yang dilaksanakan dalam penelitian

Pada saat tercapai kesetimbangan ketika pengujian DHL air tanah dilakukan, maka berlaku hubungan persamaan

$$
\frac{R_{1}}{R_{2}}=\frac{R_{3}}{R_{4}} \text { atau } R_{1}=\frac{R_{2} R_{3}}{R_{4}}
$$

Dengan demikian, Daya Hantar Listrik (DHL) sampel air dapat dirumuskan

$$
Y=\frac{1}{R_{1}}=\frac{R_{4}}{R_{2} R_{3}}
$$

Secara teoritis, nilai $R_{3}$ dibuat sama dengan $R_{4}$ agar ketelitian hasil pengukuran menjadi sangat baik (Staf Lab. Fisika Dasar UGM, 2005). 
Molekul, Vol. 4. No. 1. Mei, 2009 : 39 - 47

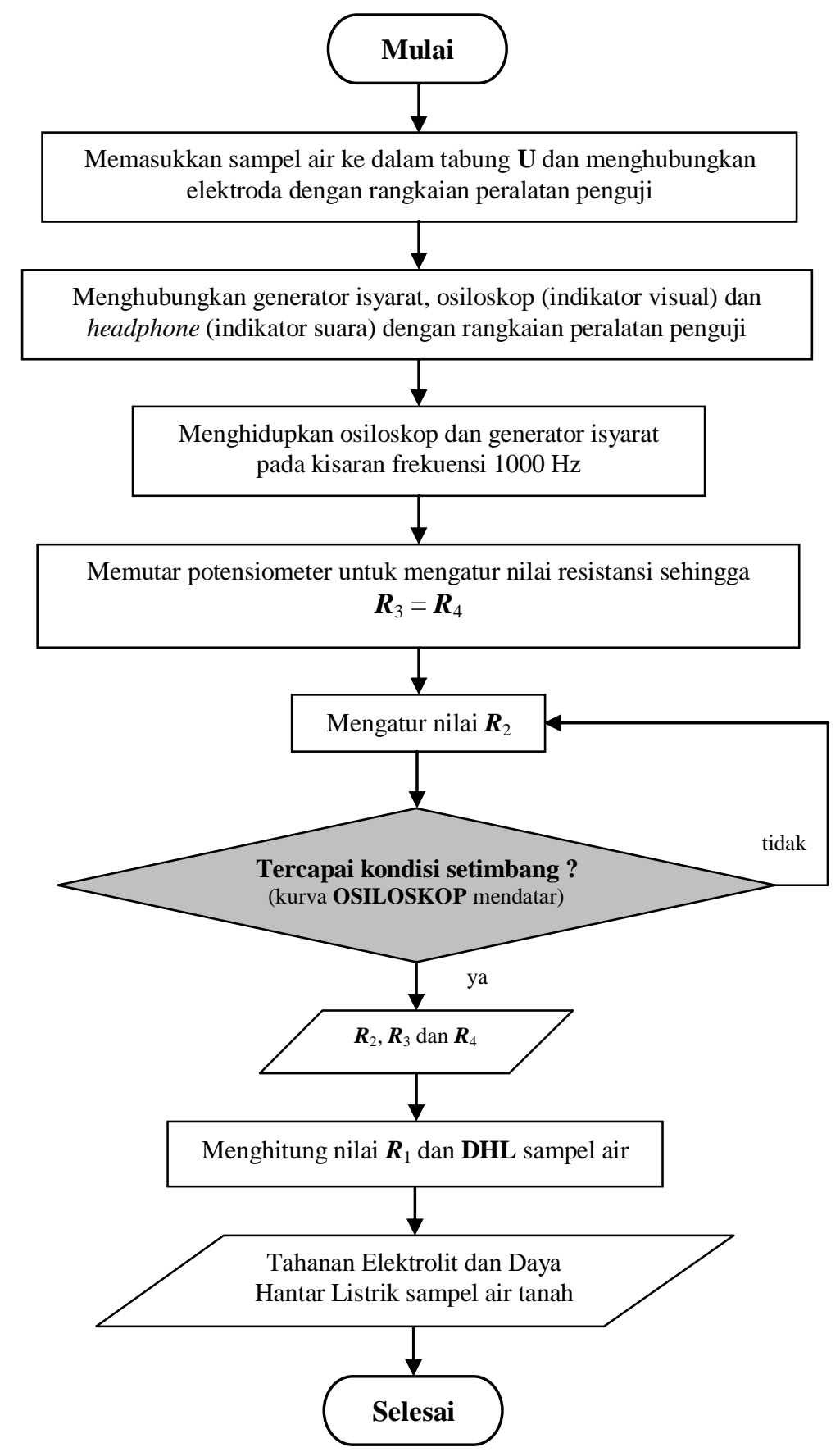

Gambar 3. Diagram alir urutan pengujian DHL sampel air tanah menggunakan prinsip jembatan Wheatstone

\section{HASIL DAN PEMBAHASAN}

Daya Hantar Listrik (DHL) air tanah telah diuji dengan peralatan seperti pada Gambar 3. Jumlah sampel air yang diuji adalah 104 buah, yang diambil dari 104 buah titik lokasi yang tersebar di sekitar TPA Gunung Tugel. Jenis manifestasi air tanah yang berhasil diambil di lokasi terdiri dari sumur, belik dan pompa air. Adapun sebaran titik lokasi dapat dilihat pada Gambar 4. 


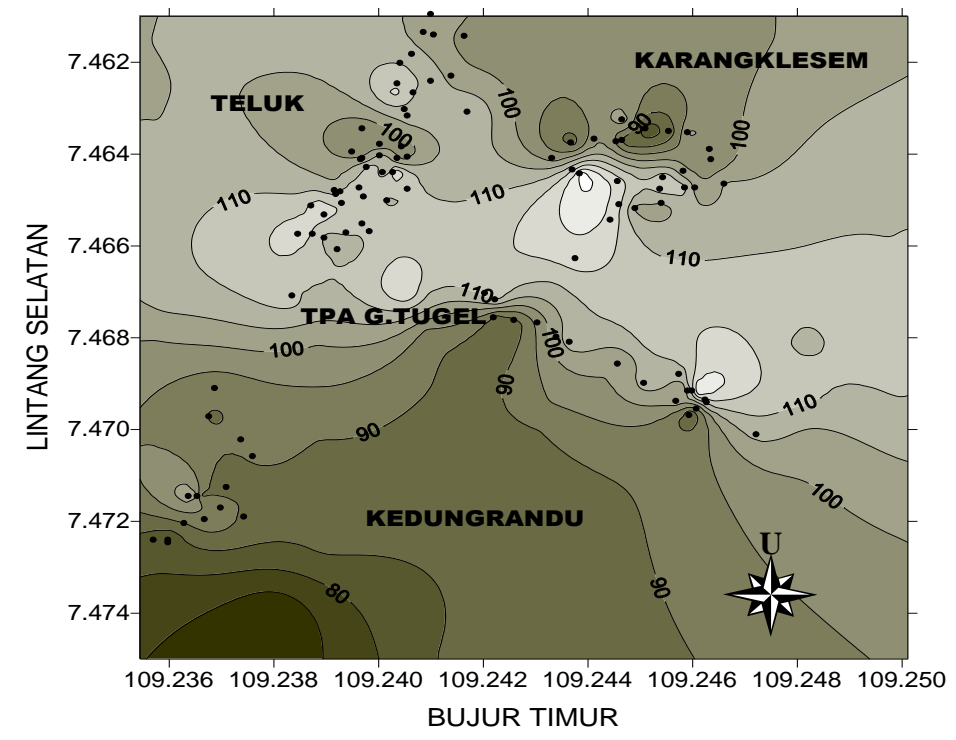

Gambar 4. Sebaran titik lokasi pengambilan sampel air tanah di atas peta topografi daerah penelitian (interval kontur 5 meter)

Sebaran titik lokasi pengambilan sampel air tanah tidak merata, karena sampel air tanah hanya dapat diambil dari sumur, belik dan pompa air yang terdapat di perkampungan penduduk. Sementara itu, sebagian besar daerah penelitian masih berupa semak, sawah, kebun, hutan dan tanah kosong yang tandus dan tidak ada manifestasi sumber air tanah.

Parameter yang diukur dalam pengujian DHL air tanah adalah beberapa nilai tahanan yang digunakan untuk menghitung nilai DHL. Hasil perhitungan DHL, diolah dan dipetakan dengan software Surfer version 7 sehingga diperoleh peta kontur DHL air tanah daerah penelitian, seperti Gambar 5. Berdasarkan peta kontur tersebut, diketahui bahwa DHL rata-rata daerah penelitian adalah $0,0594 \mathrm{k} \Omega^{-1}$, DHL tertinggi $0,1449 \mathrm{k} \Omega^{-1}$ dan DHL terendah $0,0209 \mathrm{k} \Omega^{-1}$. DHL air tanah pada titiktitik ukur di bagian selatan dan barat daya daerah penelitian relatif lebih tinggi daripada bagian utara dan timur laut. Hal ini menunjukkan bahwa arah aliran air tanah yang terkontaminasi lindi (bersifat elektrolit) akibat proses pembusukan sampah di TPA Gunung Tugel, sebagian besar menuju ke arah selatan dan barat daya (Desa Kedungrandu).

Pola aliran air tanah ini dapat dipahami, karena bagian selatan hingga barat daya daerah penelitian memiliki topografi yang lebih rendah dibandingkan dengan zona lainnya, sehingga aliran air tanah beserta air lindi menuju ke daerah tersebut. Sebagaimana diketahui topografi Gunung Tugel mempunyai satuan geomorfologi dengan bentuk permukaan berelief agak kasar, kemiringan lereng $10^{\circ}-30^{\circ}$ dengan ketinggian $75 \mathrm{~m}-120 \mathrm{mdpl}$ (Anonim, 2006). Selain itu, proses geomorfologi yang berkembang di daerah ini adalah pelapukan, erosi dan tanah longsor, sehingga tingkat kelulusan air di dalam tanah (permeabilitas) cukup besar. 


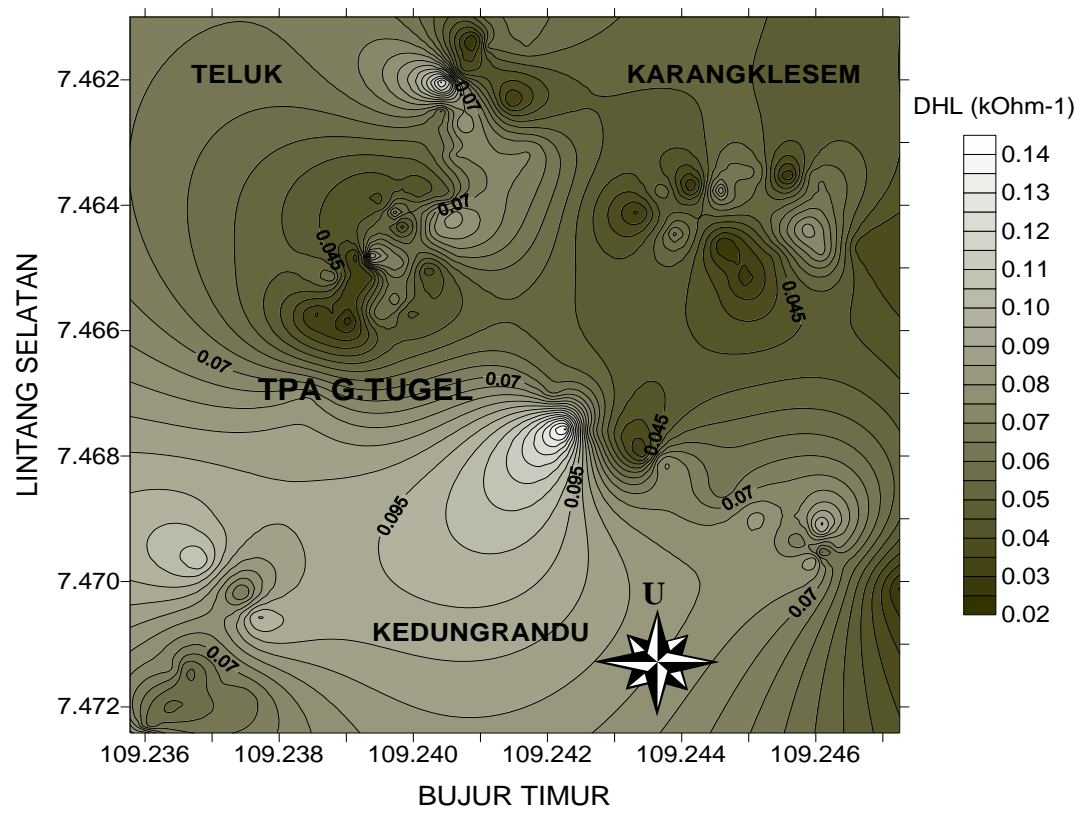

Gambar 5. Peta kontur DHL air tanah di daerah sekitar TPA Gunung Tugel.

Kondisi geologi daerah penelitian juga mendukung penyebaran air lindi. Geologi daerah Gunung Tugel berbentuk formasi Tapak yang terdiri dari satuan batupasir kasar kehijauan dan konglomerat. Batupasir kasar tersebut berselingan dengan batulempung berwarna abu-abu keputihan, lunak dan plastis dengan tebal tanah penutup kirakira 2 hingga 4 meter. Batupasir ini mempunyai ukuran butiran sedang hingga kasar serta porositas sedang hingga tinggi sehingga mudah diterobos oleh air tanah yang telah terkontaminasi lindi. Formasi Tapak diperkirakan memiliki kedalaman kira-kira 500 meter, sehingga air tanah yang terkontaminasi oleh lindi dapat terinfiltrasi ke dalam sumur penduduk yang berada dalam zona ini (Asikin dkk., 1992 dan Ruswanto dkk., 1999).
Kriteria baku mutu air golongan A hingga D berdasarkan nilai DHL dalam satuan mikro mho disajikan pada Tabel 1. Baku mutu air golongan $D$ merupakan golongan air yang tidak digunakan untuk keperluan golongan $\mathrm{A}, \mathrm{B}$, dan $\mathrm{C}$, namun masih memenuhi syarat untuk kehidupan biota air. DHL air tanah yang diperoleh dalam penelitian ini apabila dikonversi ke dalam satuan mikro mho adalah DHL rata-rata 59,4 mikro mho, DHL tertinggi 144,9 mikro mho dan DHL terendah 20,9 mikro mho. Hasil yang diperoleh ini menunjukkan bahwa DHL air tanah di daerah sekitar TPA Gunung Tugel masih berada di bawah nilai ambang batas Baku Mutu Air yang dipersyaratkan. Namun hal ini belum menunjukkan keamanan air tersebut untuk dikonsumsi, karena masih ada parameter fisika dan kimia lain yang harus diteliti. 
Tabel 1. Baku mutu air golongan A hingga D (Wardhana, 2004)

\begin{tabular}{clc}
\hline No. & \multicolumn{1}{c}{ Jenis Baku Mutu Air } & $\begin{array}{c}\text { Daya Hantar Listrik } \\
\text { (mikro mho) }\end{array}$ \\
\hline 1 & Baku mutu air golongan A: Air minum & 500 \\
2 & Baku mutu air golongan B: Perikanan & 500 \\
3 & Baku mutu air golongan C: Pertanian & 750 \\
4 & Baku mutu air golongan D: Lainnya & 1000 \\
\hline
\end{tabular}

\section{KESIMPULAN DAN SARAN}

\section{Kesimpulan}

Dari keseluruhan kegiatan penelitian yang telah dilakukan, dapat diambil kesimpulan sebagai berikut:

1. Berdasarkan hasil penelitian, diperoleh hasil bahwa DHL rata-rata daerah penelitian $0,0594 \mathrm{k} \Omega^{-1}$, DHL tertinggi $0,1449 \mathrm{k} \Omega^{-1}$ dan DHL terendah $0,0209 \mathrm{k} \Omega^{-1}$. DHL air tanah pada titik-titik ukur di bagian selatan dan barat daya daerah penelitian relatif lebih tinggi daripada bagian lainnya. Hal ini mengindikasikan bahwa aliran air tanah yang terkontaminasi lindi, sebagian besar menuju ke arah selatan dan barat daya.

2. Faktor-faktor yang berpengaruh terhadap pola dan arah aliran air tanah yang terkontaminasi lindi di daerah sekitar TPA Gunung Tugel adalah topografi dan geologi. Daerah selatan dan barat daya TPA Gunung Tugel memiliki topografi yang lebih rendah sehingga aliran air tanah yang terkontaminasi lindi menuju ke daerah tersebut. Kondisi geologi daerah setempat yang terdiri dari satuan-satuan batuan bawah permukaan yang permeabilitasnya tinggi juga ikut mendukung penyebaran air tanah yang terkontaminasi lindi.

\section{Saran-Saran}

1. Perlu dilakukan pengujian yang lebih lengkap terhadap sifat-sifat sampel air tanah, tidak hanya sifat Daya Hantar Listrik (DHL) saja, tetapi sifat-sifat fisika dan kimia lainnya.

2. Perlu dilakukan survei geofisika (misalnya geolistrik tahanan jenis), untuk menginterpretasi model pola sebaran dan kedalaman limbah cair bawah permukaan secara visual. 


\section{DAFTAR PUSTAKA}

Anonim, 2006, Kajian Gerakan Tanah di Grumbul Gunung Tugel, Desa Kedungrandu Kecamatan Patikraja, Kabupaten Banyumas, Dinas Pertambangan Sumber Daya Air Pertambangan dan Energi, Kabupaten Banyumas, Purwokerto.

Asikin S, Handoyo A., Busono H., 1992, Peta Geologi Lembar Purwokerto, Jawa, Pusat Penelitian dan Pengembangan Geologi (P3G), Bandung.

Koran Sore Wawasan, 15 Juli 2006, Penanganan Sampah Minim, Petani Merasa Dirugikan, diakses bulan Januari 2007, Sumber: http://www.wawasan digital.com.

Lubis, Fajar Rachmat, 2006, Air Sebagai Parameter Kendali dalam Tata Ruang, Inovasi Online, Edisi Volume 7/XVIII/Juni 2006, diakses bulan Januari 2007, Sumber: $\quad$ http://io.ppijepang.org/article.php?id=171.

Noriko, Nita, 2003, Tinjauan Ekologis Tempat Pemusnahan Akhir Bantar Gebang Bekasi, Makalah Majalah Sains, Program Pascasarjana, Institut Pertanian Bogor, diakses bulan Januari 2007, Sumber: http://tumoutou.net/6sem2_023 /nita noriko.htm.

Ruswanto, Nandang dan Bambang. E. P., 1999, Pemetaan geologi Lingkungan Daerah Purwokerto dan Sekitarnya, Jawa Tengah (Pemetaan Geologi Lingkungan untuk Menunjang Perencanaan tata Ruang dan Pengolahan Lingkungan, Direktorat Geologi Tata Lingkungan, Purwokerto.

Staf Lab. Fisika Dasar, 2005, Panduan Praktikum Fisika Dasar Semester 2, Laboratorium Fisika Dasar, Jurusan Fisika, Fakultas Matematika dan Ilmu Pengetahuan Alam, Universitas Gadjah Mada, Yogyakarta.

Wardhana, W.A., 2004, Dampak Pencemaran Lingkungan, Edisi revisi, Andi Offset, Yogyakarta.

Wakatsuki, T., S. Luanmanee, T. Masunaga, and $\mathrm{T}$. Attanandana. 2001. High Grade On-Site Treatment of Domestic Wastewater And Polluted River Water By Multi-Soil Layering Method. Ecological Engineering, Elsevier (in press). 